NASA Technical Memorandum 107179

\title{
Lewis Research Center: Commercialization Success Stories
}

Ann O. Heyward

Lewis Research Center

Cleveland, Ohio

Prepared for the

Space Technology and Applications International Forum cosponsored by Defense Nuclear Agency, National Aeronautics and Space Administration, United States Department of Energy, and United States Air Force Albuquerque, New Mexico, January 7-11, 1996

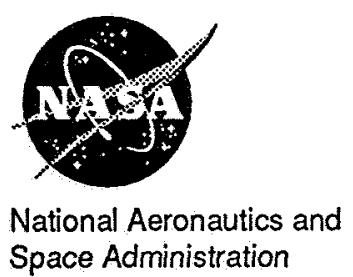

Space Administration 
Trade names or manufacturers' names are used in this report for identification only. This usage does not constitute an official endorsement, either expressed or implied, by the National Aeronautics and Space Administration. 


\title{
LEWIS RESEARCH CENTER: COMMERCIALIZATION SUCCESS STORIES
}

\author{
Ann O. Heyward \\ Office Of Interagency and Industry Programs \\ NASA Lewis Research Center \\ M.S. 3-7, 21000 Brookpark Rd. \\ Cleveland, Ohio 44135 \\ (216) 433-3484
}

\begin{abstract}
The NASA Lewis Research Center, located in Cleveland, Ohio, has a portfolio of research and technology capabilities and facilities that afford opportunities for productive partnerships with industry in a broad range of industry sectors. In response to the President's agenda in the area of technology for economic growth (Clinton/Gore 1993), the National Performance Review (1993), NASA's Agenda for Change (1994), and the needs of its customers, NASA Lewis Research Center has sought and achieved significant successes in technology transfer and commercialization. This paper discusses a sampling of Lewis Research Center's successes in this area, and lessons learned that Lewis Research Center is applying in pursuit of continuous improvement and excellence in technology transfer and commercialization.
\end{abstract}

\section{INTRODUCTION}

The National Aeronautics and Space Administration (NASA) and its Lewis Research Center face new challenges to demonstrate the relevance and worth of research and development efforts in aeronautics and space - and so demonstrate return on taxpayer investment - in an environment where increasing demands are being placed on limited resources. One mechanism for achieving maximum impact, relevance and worth from NASA's R \& D activities is through technology transfer and commercialization. While technology transfer is not a new part of NASA's mission, it is a mission where expectations and visibility have evolved and risen rapidly. New expectations have redefined the relationship between technology transfer and the demonstration of the relevance and worth of individual research and technology development programs.

As NASA's lead Center and Center of Excellence in Aeropropulsion, Lewis conducts research and technology development in subsonic, supersonic, hypersonic and high performance aircraft propulsion systems - supported by research in materials, structures, internal fluid mechanics, instrumentation and controls, interdisciplinary technologies and aircraft icing. Lewis is also a Center of Excellence in Microgravity Science, researching combustion science and fluid physics. Lewis Research Center is NASA's lead Center for Commercial Communications Technology. The Center also performs research and technology development in Spacecraft Power and on-board Propulsion. Lewis Research Center is committed to the mission of developing partnerships and transferring technologies developed through its programs to benefit both aerospace and non-aerospace sectors of the U.S. economy; virtually all of its program areas have resulted in new products in the commercial marketplace, generally achieved through collaborative relationships with industry that respond to customer needs. In order to increase quality, customer satisfaction, and participation in these kinds of partnerships, Lewis Research Center has introduced a number of organizational and process innovations.

\section{INNOVATIONS IN DOING BUSINESS}

NASA Lewis Research Center has pursued new ways of doing business in the arena of technology transfer and commercialization, in response to national needs. This pursuit has resulted in fundamental changes in organization and process, which are resulting in increased effectiveness and responsiveness to customer needs. 


\section{A New Organization for Increased Effectiveness}

In response to the National Performance Review for NASA, NASA's Agenda for Change, and the needs of its customers, NASA Lewis Research Center has realigned its technology transfer and commercialization organization. NASA Lewis Research Center's Office of Interagency and Industry Programs is designed to provide for increased effectiveness in carrying out the technology transfer mission, primarily defined through economic impact; provide for closer local, state, and regional stakeholder relationships with Lewis Research Center; and provide easier access to Lewis Research Center technologies by industry, particularly small businesses. Lewis Research Center's Office of Interagency and Industry Programs is made up of four primary and one supporting cross-functional and fluid teams: Marketing, Technical Assistance, Partnership, Small Business Outreach and Project Support. The Office of Interagency and Industry Programs provides one-stop shopping for Lewis' industry customers in non-aerospace sectors, and also manages the Small Business Innovative Research (SBIR) Program. Through the Office of Interagency and Industry Programs, Lewis customers receive the benefits of a virtual organization representing the full range of expertise and technology available at the Lewis Research Center, regardless of the internal organization in which it originates. The Center's Marketing Team serves a dual function of outreach to the business community and feedback to Lewis Research Center of customer needs and emerging trends. The Partnerships Team implements and facilitates the establishment of formal arrangements with industry customers - such as Space Act and cooperative agreements. The Technical Assistance Team provides problem solving and matches Lewis customers with the appropriate expertise within Lewis Research Center's project, research and development organizations. The Small Business Outreach Team manages the SBIR Program and is a single access point for the other services provided by the Commercial Technology Office. The Project Support Team creates and supports electronic access to the Office and collects and analyzes data regarding the impact and effectiveness of Lewis' activities in technology transfer and commercialization.

Uniquely among all NASA Centers, the Office of Interagency and Industry Programs is advised by an external board composed of representatives of local business and industry, local and regional technology transfer organizations, local, state and regional economic development organizations, and other government agencies in the region. Advisors are asked to assess Lewis Research Center programs and approaches to technology transfer and commercialization, and to provide their perspective on opportunities for continuous improvement and innovation in service to the business community and in economic impact.

\section{The Technology Dialogue Series}

The "Technology Dialogue" program is a joint effort of the NASA Lewis Research Center, Enterprise Development, Inc.(EDI), a Cleveland business incubator, and the Great Lakes Industrial Technology Center (GLITeC), NASA's Midwest Regional Technology Transfer Center. The series began as a pilot program in 1994. Representatives of local industry, identified by the Center, GLITeC and EDI as having potential interest, are invited by the Lewis Research Center Director to participate in a meeting focused on a particular technology. Each such dialogue is opened by a Lewis Research Center scientist or engineer presenting a technology available for industrial application; a participating industry representative also presents an available technology or a specific problem requiring a solution. Opportunity for dialogue and problem solving is provided to participants in an informal atmosphere that fosters open communication, creative thinking, and mutual learning. As a result of its first three such dialogues, Lewis has entered into a formal partnership with one participant to explore applications of a method for creating affordable composite materials. Less measurable benefits are also worth noting: Lewis has established a relationship with many new industrial customers with which the Center had not previously interacted; the participating companies have shared their needs for new technologies, providing the Center with potential future opportunities for technology application; Lewis participants have gained a better understanding of the business challenges - as well as technological challenges - facing Cleveland's industry community.

Based on the success of the pilot program in creating a new partnership, and on the positive feedback received from participants, Lewis has since expanded the Technology Dialogue Series to locations throughout the State of Ohio. A series of ten such dialogues will be held in 1995-1996. 


\section{Reinventing the Space Act Agreements Process}

The Space Act Of 1958, which created the National Aeronautics and Space Administration, states that NASA is to "provide for the widest practical and appropriate dissemination of information concerning its activities and the results thereof." In order for NASA to accomplish this, the Space Act permits NASA to enter into agreements with public and private entities to engage in cooperative relationships and activities. These "Space Act" agreements are one of NASA's primary mechanisms for entering into cooperative relationships with industry and with state and local economic development organizations. While Space Act agreements can be said to be analogous to other agencies' Cooperative Research and Development Agreements (CRADAs), the Space Act affords NASA unique flexibility in creating these collaborative relationships. This flexibility is not unlimited, however; Space Act agreements must conform to a number of statutory requirements. As a consequence, there are basic elements all such agreements must contain.

Prior to its examination and reinvention of the Space Act agreements process beginning in 1992, Lewis Research Center's experience in creating and securing approval by all parties for such agreements was that the process customarily took approximately a calendar year to complete. Clearly, the Center's industry customers required a much shorter time frame to initiate collaborative arrangements, particularly where the activity concerned focused, problem-solving or analytical efforts in response to market forces. NASA Lewis Research center developed "standard" agreements and routings, and made the documents available electronically to scientists, engineers and managers across the Center. Preparation and approval time for Space Act Agreements at Lewis

Research Center has now been reduced by $83 \%$, to a norm of one month. In one technical directorate alone, the number of new Space Act agreements initiated increased ten-fold within two years (from 6 in the year prior to the "standard" agreements' introduction to sixty in the two years following implementation).

\section{CUSTOMER-FOCUSED PARTNERSHIPS AND ALLIANCES}

NASA Lewis Research Center is currently engaged in over 500 partnerships with industry, academia, and other local, state, and federal government agencies, implemented through Space Act, cooperative, and interagency agreements, and other contractual, licensing and consortium arrangements. These partnerships provide the basis for successful collaboration in bringing new products to the marketplace. A representative sample of successful Lewis partnerships - using various partnership approaches - are presented below.

\section{Technical Assistance Successes}

Relatively small investments of time and resources in providing technical assistance have resulted in significant benefits to NASA Lewis Research Center's customers.

A Cleveland, Ohio electronics company was presented with the opportunity to provide thousands of automotive cellular antennas to an auto manufacturer in Germany. While the manufacture of an outstanding quality antenna was well within their capabilities, they did not have the necessary facilities to demonstrate that the antenna they could manufacture could meet the electrical performance requirements specified by the car maker. After contacting NASA Lewis Research Center's Office of Interagency and Industry Programs, the company was matched with experts in Lewis' Space Electronics Division. In a few short hours in an antenna characterization laboratory, two Lewis engineers provided the company with the performance information they needed to demonstrate that their antenna met their customer's requirements. The electronics company won the contract to produce the antennas for the car company; six people were employed in their plant in the manufacturing of the units.

A Cleveland manufacturer of aircraft parts needed to redesign a particular product in response to changes in Federal Aviation Administration regulations. They approached the Great Lakes Industrial Technology Center (GLITeC) - NASA's Midwest Regional Technology Transfer Center - who identified expertise and software at Lewis Research Center which could meet their needs. Lewis researchers used a computational fluid dynamics code to predict performance of the product part, and transferred the software to the company. The company now 
has the capability to re-design the part and increase its sales in both domestic and overseas markets. The company estimates that the assistance it received from Lewis. Research Center, through GLITeC, saved the company $\$ 20,000.00$ in time and labor in acquiring data and modeling expertise necessary to design the final product.

\section{Space Act and Interagency Agreements}

Kirby, a vacuum cleaner manufacturer located in Cleveland, Ohio, is seeking to improve their products by reducing the noise associated with the vacuum cleaners' fans. Through a Space Act Agreement, NASA Lewis Research Center is working with the company on a variety of joint projects. The Center's Propulsion Systems Branch has assisted the company in its product improvement efforts. Software originally developed for simulating the airflow through jet engine fans is being used to understand the performance of vacuum cleaner fans. NASA Lewis has trained a Kirby engineer to use the simulation software. In addition to the simulation capabilities afforded by the software, NASA Lewis also provided access to its holography laboratory, where fans are studied with lasers to analyze vibrations that are too subtle to detect through visual inspection. Vibration in operation can affect both the performance and life of the fan in a commercial product. The company estimates that cost savings resulting from assistance NASA Lewis has provided is from $\$ 10,000.00$ to $\$ 50,000.00$ in software costs alone.

The U.S. Department of Agriculture's Forest Products Laboratory worked to develop new, thinner saw blades for use in lumber production. They made very significant progress in developing new blade geometries, identifying factors in blade instability, and identifying new alloys for saw blade fabrication. The new alloys had several desirable properties - low thermal expansion, in particular, which is of benefit in an operating environment where the saw blade is subjected to considerable heat through friction. However, the rolling process which was used to create the thin blade stock left residual stresses in the blades which cause warping - limiting their effectiveness and marketability for full production use. The USDA Forest Products Laboratory received assistance from Lewis experts in materials, structures, and instrumentation, which has resulted in a heat-treating process which eliminated the residual stress problem. and increased blade strength by over $12 \%$. NASA Lewis, through a Space Act Agreement with the commercial maker of the alloy, will transfer the heat treatment technology for application in the manufacture of saw blades. NASA Lewis will also assist the company in scaling the process to full production. At this time, it appears that the scope of the impact of this joint effort between USDA and NASA will extend far beyond the commercial benefits to the manufacturer of the blades; the new thinner blades are expected to increase the amount of usable lumber gained from each $\log$ by $5 \%$, which could lead to over 2 million trees saved each year, and a $4-5 \%$ cost reduction in new housing costs. In turn, the reduction in new housing costs could lead to increased new housing starts and increased demand for additional consumer products. In short, the new blades could mean that 1 billion board feet of lumber will be recovered from what otherwise would be sawdust and waste wood - benefiting our environment and our economy.

\section{The Advanced Coatings and Surface Texturing Consortium}

NASA Lewis Research Center and its Regional Technology Transfer Center - the Great Lakes Industrial Technology Center (GLITeC) - have established the Advanced Coatings and Surface Texturing Consortium to provide access for industry to the specialized expertise and facilities of Lewis' Electrophysics Branch, which does advanced applied research in the area of specialized coatings and surface texturing techniques. Consortium members invest at a specified level $-\$ 10,000.00$ - in a reimbursable, "umbrella" Space Act Agreement between GLITeC and the NASA Lewis Research Center. Since the agreement is pre-existing, new consortium members can be added through execution of an agreement with GLITeC in a matter of days. Consortium Members receive consultation on advanced texturing processes and coatings most suited to their needs, coating and texturing of member-supplied samples to test new approaches and applications, and consultation on member-performed evaluation of samples. Benefits to members include cost savings through thorough evaluation of approaches prior to full-scale investment in product development or new production capabilities. Industrial applications areas include biomedical products, lenses, windows, barriers, shields, seals, cutting blades and surfaces, food, and magnetic storage media. 
Currently, the consortium has 6 participating companies (several are renewal members), who have made a combined total investment of seventy thousand dollars in their partnership with Lewis Research Center. So far, these efforts have resulted in product improvements in the food, biomedical, and plumbing industries. As a result of marketing the capabilities of the consortium, 13 additional agreements have been initiated, with a combined total industry investment value of on hundred twenty thousand dollars.

This same expertise is also available via individual partnerships with the NASA Lewis Research Center, facilitated through NASA's Office of Interagency and Industry Programs and GLITeC. For instance, NASA Lewis' Electrophysics Branch is working with both the Cleveland Museum of Art and the Smithsonian Institution to apply a process which exposes surfaces to atomic oxygen to the cleaning and restoration of damaged works of art - in particular, oil paintings. The method has been demonstrated to effectively and safely clean oil painting surfaces of smoke and old varnish. The techniques is also being examined for restoration of paintings done in the acrylic media which are typically employed by many modern masters. Currently, no method exists to reliably clean smoke damage from acrylic painting surfaces; it is possible that the atomic oxygen bombardment technique that is available to consortium members for industrial applications will be a breakthrough in the arena of our national artistic heritage and culture as well. (Stern, 1995)

\section{SUMMARY AND CONCLUSIONS}

In response to the President's agenda in science and technology, the National Performance Review, NASA's Agenda for Change, and - most importantly - the needs of its customers, the Lewis Research Center continues to seek new successes in technology transfer and commercialization. In order to do so, the Center has fundamentally changed its technology transfer and commercialization organization and its business processes in order to more effectively respond to customer needs. The successes achieved thus far have provided valuable "lessons learned," which NASA Lewis Research Center will continue to apply as new opportunities in technology transfer and commercialization are pursued.

Lewis Research Center has capitalized on its strengths in carrying out its technology transfer and commercialization mission. The successful efforts presented have each represented the application of an area of expertise in which Lewis Research Center has excelled by virtue of the demands of its missions in aeronautical propulsion, the disciplines of materials , structures, and instrumentation, its roles in space power and on-board propulsion technology development, and its role as a lead center in commercial space communications. The linkage between the Center's research and technological missions and capabilities and the areas in which it has achieved substantial success in technology transfer and commercialization is critical and unbreakable. Exploiting this linkage to its full potential is, in effect, structuring "product lines" around core competencies - a strategic approach common in technology-based industries.

An excellent example of success through this approach is set by Lewis' own CARES (Ceramic Analysis and Reliability Evaluation of Structures) software development team. CARES is a unique family of software codes which predict reliability and life of structures made from ceramics and other brittle materials. The software is a product of the unique strengths in structural modeling and life prediction of the Lewis Research Center. The modeling and prediction capability provided by the software is in demand by an extraordinary range of industries for products that are very different from the software's original application to life prediction for ceramic aircraft engine structures. Since its development, CARES has been used to develop products that include glass cathode ray tubes, ceramic hip joints, and ceramic tooth crowns. The software is in use by more than 100 customers. The CARES team - which took a fundamental, core competency and applied it to an enormous range of customer applications - has been honored with the NASA Software of the Year Award in 1994, the Federal Laboratories Consortium Award for Excellence in Technology Transfer, and was co-recipient with Phillips of a 1995 "R \& D 100" award from $R \& D$ Magazine.

Faster and easier access to technological expertise - "cutting red tape" - can powerfully affect a laboratory's performance in the arena of technology transfer and commercialization. This was Lewis Research Center's experience as a result of the reinvention of the Space Act agreement preparation and approval process, and as a 
lesson learned from the success of the Advanced Coatings and Surface Texturing Consortium and the Technology Dialogue Series. NASA Lewis Research Center continues to expand the latter programs, is developing new consortia, and has realigned its technology transfer and commercialization structure to provide direct and immediate access to Lewis Research Center's capabilities. NASA Lewis Research Center is currently engaged in over 500 partnerships of various types. This total has been reached through a substantial number of new partnerships formed within the last few years, as Lewis reduced the time and effort required to engage in partnership through Space Act agreements.

It is critically important to recognize and reward participation and success in technology transfer and commercialization efforts. Rewarding participation in this NASA mission sends a powerful message of encouragement and support for technology transfer and commercialization efforts. Aggressive pursuit of recognition for participants in technology transfer and commercialization efforts has resulted in an increased level of participation in these activities at NASA Lewis Research Center.

Achieving external recognition for new commercial products and industry impact also provides outreach benefits for the laboratory - serving as an extremely effective marketing mechanism for reaching new potential customers. Within the last year, Lewis Research Center was recognized with five prestigious "R \& D 100" awards - $-\underline{R}$ \& D Magazine's recognition of the 100 most technologically significant developments of the last year. Each winning product represented the joint efforts of Lewis and one or more industry and university partners. To date, Lewis

Research Center has received follow-up inquiries regarding three of the five winning products. In each case, the party making the inquiry first heard of the product in the context of its recognition by $R$ \& $D$ Magazine, even though each of the products in question had received publicity in other contexts prior to the award competition. This increased product visibility - most importantly - means additional visibility and potential for commercial success for Lewis Research Center's partners.

\section{Acknowledgments}

Appreciation is extended to the many companies and organizations with which Lewis Research Center is privileged to work in technology transfer and commercialization efforts of mutual benefit. In particular, thanks are extended to the Kirby Company; the Cleveland Museum of Art; the Smithsonian Institution; the USDA Forest Products Laboratory; the members of the Advanced Coatings and Surface Texturing Consortium; the Philips Display Components Company, and many others. Grateful acknowledgment is made of the efforts of Lewis Research Center scientists, engineers, and managers in creating and supplying the technology and expertise that make commercialization and technology transfer possible, and in participating vigorously and enthusiastically in the technology commercialization and transfer mission. The support of NASA's Office of Space Access and Technology and its Commercial Development and Technology Transfer Division is also acknowledged with thanks. Finally, the dedicated efforts of the staff of NASA Lewis' Office of Interagency and Industry Programs, the staff of the Great Lakes Industrial Technology Center, and the staff of Enterprise Development, Inc. are acknowledged with much gratitude.

\section{$\underline{\text { References }}$}

Clinton, President William J., and Gore, Vice President Albert, Jr. (1993) Technology for America's Economic Growth, A New Direction to Build Economic Strength, February 22, 1993.

Staff of the National Performance Review, Office of the Vice President (1993) National Aeronautics and Space Administration (Accompnaying Report of the National Performance Review), September 1993.

NASA Commercial Technology Team (1994), NASA Commercial Technology: Agenda for Change, July 1994. Stern, Cassandra (1995) "How Rocket Science Helps Clean Dirty Art," The Washington Post, September 13, 1995.

"33rd Annual R \& D 100 Awards," $R$ \& D Magazine, September, 1995. 


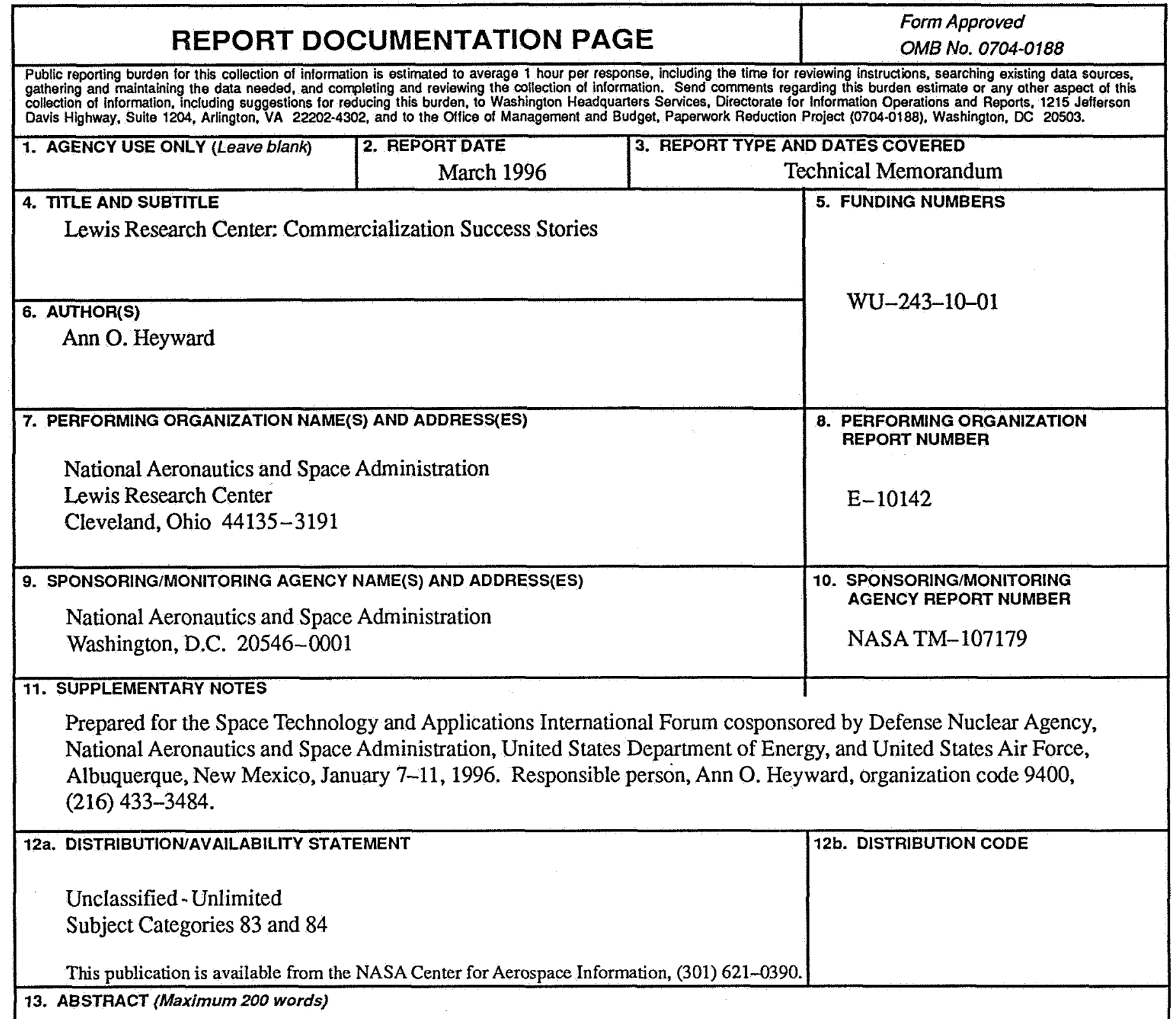

The NASA Lewis Research Center, located in Cleveland, Ohio, has a portfolio of research and technology capabilities and facilities that afford opportunities for productive partnerships with industry in a broad range of industry sectors. In response to the President's agenda in the area of technology for economic growth (Clinton/Gore 1993), the National Performance Review (1993), NASA's Agenda for Change (1994), and the needs of its customers, NASA Lewis Research Center has sought and achieved significant successes in technology transfer and commercialization. This paper discusses a sampling of Lewis Research Center's successes in this area, and lessons learned that Lewis Research Center is applying in pursuit of continuous improvement and excellence in technology transfer and commercialization.

\begin{tabular}{|l|l|}
\hline 14. SUBJECT TERMS \\
Technology transfer; Commercialization; Partnership; Natio \\
$\begin{array}{c}\text { 17. SECURITY CLASSIFICATION } \\
\text { OF REPORT } \\
\text { Unclassified }\end{array}$ & $\begin{array}{c}\text { 18. SECURITY CLASSIFICATION } \\
\text { OF THIS PAGE } \\
\text { Unclassified }\end{array}$ \\
\hline
\end{tabular}

19. SECURITY CLASSIFICATION OF ABSTRACT
Unclassified

\begin{tabular}{l} 
15. NUMBER OF PAGES \\
06 \\
\hline $\begin{array}{c}\text { 16. PRICE CODE } \\
\text { A02 }\end{array}$
\end{tabular}

20. LIMITATION OF ABSTRACT 